\title{
Measurement report: Fast photochemical production of peroxyacetyl nitrate (PAN) over the rural North China Plain during cold-season haze events
}

5 Yulu Qiu ${ }^{1,2,3,4}$, Zhiqiang $\mathrm{Ma}^{1,3,4,{ }^{*}}$, Ke $\mathrm{Li}^{5}$, Mengyu Huang ${ }^{6}$, Jiujiang Sheng ${ }^{6}$, Ping Tian ${ }^{6}$, Jia Zhu², Weiwei $\mathrm{Pu}^{3,4}$, Yingxiao Tang ${ }^{7}$, Tingting Han ${ }^{3,4}$, Huaigang Zhou ${ }^{3,4}$, and Hong Liao ${ }^{2}$

${ }^{1}$ Institute of Urban Meteorology, China Meteorological Administration, Beijing, 100089, China

${ }^{2}$ Collaborative Innovation Center of Atmospheric Environment and Equipment Technology, Jiangsu Key Laboratory of Atmospheric Environment Monitoring and Pollution Control (AEMPC), School of Environmental Science and Engineering,

10 Nanjing University of Information Science \& Technology, Nanjing, 210044, China

${ }^{3}$ Beijing Shangdianzi Regional Atmosphere Watch Station, Beijing, 101507, China

${ }^{4}$ Environmental Meteorology Forecast Center of Beijing-Tianjin-Hebei, Beijing, 100089, China

${ }^{5}$ John A. Paulson School of Engineering and Applied Sciences, Harvard University, Cambridge, MA 02138, USA

${ }^{6}$ Beijing Weather Modification Office, Beijing, 100089, China

$15 \quad{ }^{7}$ Tianjin Environmental Meteorology Center, Tianjin, 300074, China

Correspondence to: Zhiqiang Ma (zqma@ium.cn)

Abstract. Photochemical pollution over the North China Plain (NCP) are attracting considerable concern. Peroxyacetyl nitrate (PAN) is usually viewed as the second most important photochemical pollutant featuring high mixing ratios during warm seasons. Our observations at a background site in the NCP identified high PAN concentrations even during coldseason haze events. The abrupt increasing rates of PAN by $244 \%$ and $178 \%$ over the morning hours (8:00-12:00) on 10/20 and 10/25, 2020 were 10.6 and 7.7 times those on clean days. The pollution days were characterized by higher temperature and humidity, accompanied by anomalous southerlies. Enhanced local photochemistry has been identified as the dominant factor that controls PAN increase in the morning at the rural site, as the time when prevailing wind turned to southerlies was too late to facilitate direct transport of PAN from the polluted urban region. By removing the effect of direct transport of PAN, we provide a quantitative assessment of net PAN chemical production rate of $0.45 \mathrm{ppb} \mathrm{h}^{-1}$ on the polluted morning, also demonstrating the strong local photochemistry. Using observations and calculated photolysis rates, we find that oxidation of acetaldehyde by hydroxyl radical $(\mathrm{OH})$ is the primary pathway of peroxyacetyl radical formation at the rural site. Acetaldehyde concentrations and production rates of $\mathrm{HO}_{\mathrm{x}}\left(\mathrm{HO}_{\mathrm{x}}=\mathrm{OH}+\mathrm{HO}_{2}\right)$ radical on pollution days were 2.8 and 2 times that on clean days, respectively, leading to the abrupt increase of PAN in the morning. Formaldehyde (HCHO) photolysis dominates the daytime $\mathrm{HO}_{x}$ production thus contributing to fast photochemistry of PAN. Our observational results fully explain the cause of rapid increase of PAN during cold days at a rural site of the NCP, as well as provide the evidence of important role of $\mathrm{HCHO}$ photolysis in secondary pollutants at lower nitrogen oxide emissions. This highlights the imperative to implement strict volatile organic compounds controls out of summer seasons over the NCP. 


\section{Introduction}

Since the late 1960s, peroxyacetyl nitrate (PAN) has been identified as a key photochemical pollutant in the atmosphere, having adverse effects in human health and vegetation (Heuss and Glasson, 1968; Taylor, 1969). It is a secondary pollutant formed through reactions between peroxyacetyl radical $\left(\mathrm{CH}_{3} \mathrm{C}(\mathrm{O}) \mathrm{O}_{2}\right.$, $\left.\mathrm{PA}\right)$ and nitrogen dioxide $\left(\mathrm{NO}_{2}\right)$ (Xue et al., 2014). The dominant three pathways of PA formation are through oxidation of acetaldehyde $\left(\mathrm{CH}_{3} \mathrm{CHO}\right)$, photolysis of acetone $\left(\mathrm{CH}_{3} \mathrm{C}(\mathrm{O}) \mathrm{CH}_{3}\right)$ and methylglyoxal $\left(\mathrm{CH}_{3} \mathrm{COCHO}\right.$, MGLY) (Fischer et al., 2014):

$$
\begin{aligned}
& \mathrm{CH}_{3} \mathrm{CHO}+\mathrm{OH} \rightarrow \mathrm{PA}+\mathrm{H}_{2} \mathrm{O} \\
& \mathrm{CH}_{3} \mathrm{C}(\mathrm{O}) \mathrm{CH}_{3}+h v \rightarrow \mathrm{PA}+\mathrm{CH}_{3} \\
& \mathrm{CH}_{3} \mathrm{COCHO}+h v \rightarrow \mathrm{PA}+\mathrm{HCO}
\end{aligned}
$$

PAN can be thermally decomposed back to $\mathrm{PA}$ and $\mathrm{NO}_{2}$ which is the major removal pathway in the lower troposphere:

PAN's precursors, such as $\mathrm{CH}_{3} \mathrm{CHO}$, acetone and MGLY, are usually viewed as the second-generation precursors, because they not only directly come from anthropogenic emissions but also can be oxidized by non-methane hydrocarbons (NMHCs) (Xue et al., 2014). These NMHCs are first-generation precursors of PAN. Thus, photochemical production of PAN could be determined by the oxidation of volatile organic compounds (VOCs) with hydroxyl radical (OH) in the presence of nitrogen oxide $\left(\mathrm{NO}_{\mathrm{x}}=\mathrm{NO}+\mathrm{NO}_{2}\right)$. Nitrous acid $(\mathrm{HONO})$ is usually considered as the dominant source of $\mathrm{OH}$ radical in the early morning (Alicke et al., 2003) and during cold days (Hendrick et al., 2014; Kim et al., 2014; Lu et al., 2019) that is mainly generated from direct traffic emissions and heterogeneous conversion of $\mathrm{NO}_{2}$ on ground and aerosol surfaces (Xue et al., 2020; Liu et al., 2021). In addition, photolysis of carbonyls may also greatly influence $\mathrm{HO}_{\mathrm{x}}\left(\mathrm{HO}_{\mathrm{x}}=\mathrm{OH}\right.$ $+\mathrm{HO}_{2}$ ) and ozone $\left(\mathrm{O}_{3}\right)$ production at lower $\mathrm{NO}_{\mathrm{x}}$ concentrations during cold seasons (Edwards et al., 2014; Li et al., 2021).

55 For example, $\mathrm{Li}$ et al. (2021) found that $\mathrm{HO}_{\mathrm{x}}$ radicals from photolysis of formaldehyde (HCHO) accelerated the ozone upsurge during COVID-19 in Beijing in response to substantial $\mathrm{NO}_{\mathrm{x}}$ reductions.

The North China Plain (NCP) region is now experiencing urbanization and industrial expansions, leading to air pollution as a matter of intense debate. Since 2013, the China Government has performed strict emission reduction measures and resulted in rapid decreases of $\mathrm{PM}_{2.5}$ concentration (Zhai et al., 2019). However, increases of $\mathrm{O}_{3}$ concentrations in the

60 NCP region have been frequently reported owing to large amounts of anthropogenic precursor emissions and meteorological variability so far (Ma et al., 2016; Li et al., 2020; Lu et al., 2020; Dang et al., 2021). Li et al. (2020) reported that the maximum 8h average (MDA8) $\mathrm{O}_{3}$ concentrations in summer NCP during 2013-2019 were increased by a rate of 3.3 ppb a ${ }^{-1}$. As another important photochemical pollutant, PAN pollution events were also extensively recognized both in the urban (Zhang et al., 2014; Zhang et al., 2015; Zhang et al., 2017; Qiu et al., 2019a) and rural NCP regions (Qiu et al., 2020a; Wei 65 et al., 2020) at the same time. These also confirm the severity and complexity of photochemical pollution in this highlypopulated NCP region. 
Compared with the relatively low concentration of $\mathrm{O}_{3}$ in autumn and winter seasons (Wang et al., 2013), PAN pollution events are also observed in cold days over the NCP (Zhang et al., 2014; Liu et al., 2018; Zhang et al., 2019; Zhang et al., 2020a; Qiu et al., 2019b; 2020b) associated with particulate pollution events. For example, Qiu et al. (2020b) reported a high

70 PAN level of 4.13 ppb during the COVID-19 lockdown period of January-February 2020 in Beijing, and the average value was 52\% higher than that in summer 2019 when solar radiation was intensive. A common explanation for the observed high PAN concentration in winter is its susceptibility to be accumulated under a stable atmosphere and regional transport due to decreased thermal decomposition under low temperatures (Qiu et al., 2019b; Zhang et al., 2020a). In addition, accelerated photochemistry can also play a role during PAN pollution events in cold days (Zhang et al., 2014; Liu et al., 2018; Qiu et al., 2020b; Zhang et al., 2020a) since unexpectedly high PAN concentrations are usually observed during the daytime. Thus, PAN could represent a key indicator of photochemistry in cold seasons.

Despite several field campaigns and experiment analysis in recent years, the fast PAN formation mechanisms during cold days over the NCP region still have not been fully explored so far, especially over clean rural areas. Previously, HONO photolysis was tentatively considered as the cause of enhanced local photochemistry in winter of urban NCP region, thus

80 contributing to increases in PAN concentrations (Liu et al., 2018; Zhang et al., 2020b). However, these studies neglect the impacts of carbonyl photolysis that may play a dominant role in PAN formation over the rural region where $\mathrm{NO}_{\mathrm{x}}$ emissions are rather low and could allow for fast photochemistry. The lack of integrated observation of VOCs, HONO and other related chemical species also hinders the comprehensive understanding of PAN chemistry.

Here, we first show observational evidence of fast PAN formation at a rural site of the NCP during haze events in

85 autumn 2020. The dominant contribution from enhanced local photochemistry to PAN concentration increases has been confirmed by eliminating the role of regional transport utilizing carbon monoxide (CO) as a tracer. Using simultaneous observations of PAN, VOCs, HONO, and photolysis rates, we calculate the daytime $\mathrm{HO}_{\mathrm{x}}$ production rates and reveal the contributions of precursors and radical oxidants in daytime PAN upsurge. Our results explain the formation mechanisms of PAN during cold days and investigate the cause of rapid PAN increase over the rural NCP. In this study, we provide a new

90 insight into assessing impacts of high reactive VOCs from urban plumes on atmospheric oxidation capacity and secondary pollutant formation over the rural NCP.

\section{Experiments and Methods}

\subsection{Site}

Our field campaign was conducted at the Shangdianzi (SDZ) national atmospheric background station, which is near 95 the northern border of Beijing, China $\left(40.65^{\circ} \mathrm{N}, 117.17^{\circ} \mathrm{E}, 293.9 \mathrm{~m}\right.$ a.s.l.), approximately $100 \mathrm{~km}$ northeast of the urban center (Figure 1). The sampling site is located on the roof of the station, approximately $6 \mathrm{~m}$ from the ground. The prevailing wind at night and in the morning is northeasterly and turns to southwesterly in the afternoon due to effect of local valley wind. The SDZ site is upwind of the polluted NCP region, surrounded by extensive vegetation and sparsely-populated small 
villages. The mean $\mathrm{PM}_{2.5}$ concentration in 2020 at the SDZ site is $26 \mu \mathrm{g} \mathrm{m}^{-3}$, much lower than present air quality standard in China $\left(35 \mu \mathrm{g} \mathrm{m}^{-3}\right)$. An integrated observation experiment was performed at the SDZ site from 10/13 to 10/27, 2020, including measurements of PAN, VOCs, $\mathrm{O}_{3}, \mathrm{HONO}, \mathrm{NO}_{\mathrm{x}}, \mathrm{CO}$ and photolysis rates. Besides, we also conducted PAN observations at an urban site in Beijing, located on the campus of the Minzu University of China $\left(39.95^{\circ} \mathrm{N}, 116.32^{\circ} \mathrm{E}\right)$. The urban site is between the second and third ring roads in downtown Beijing, mainly affected by traffic and residential sources.

(b)
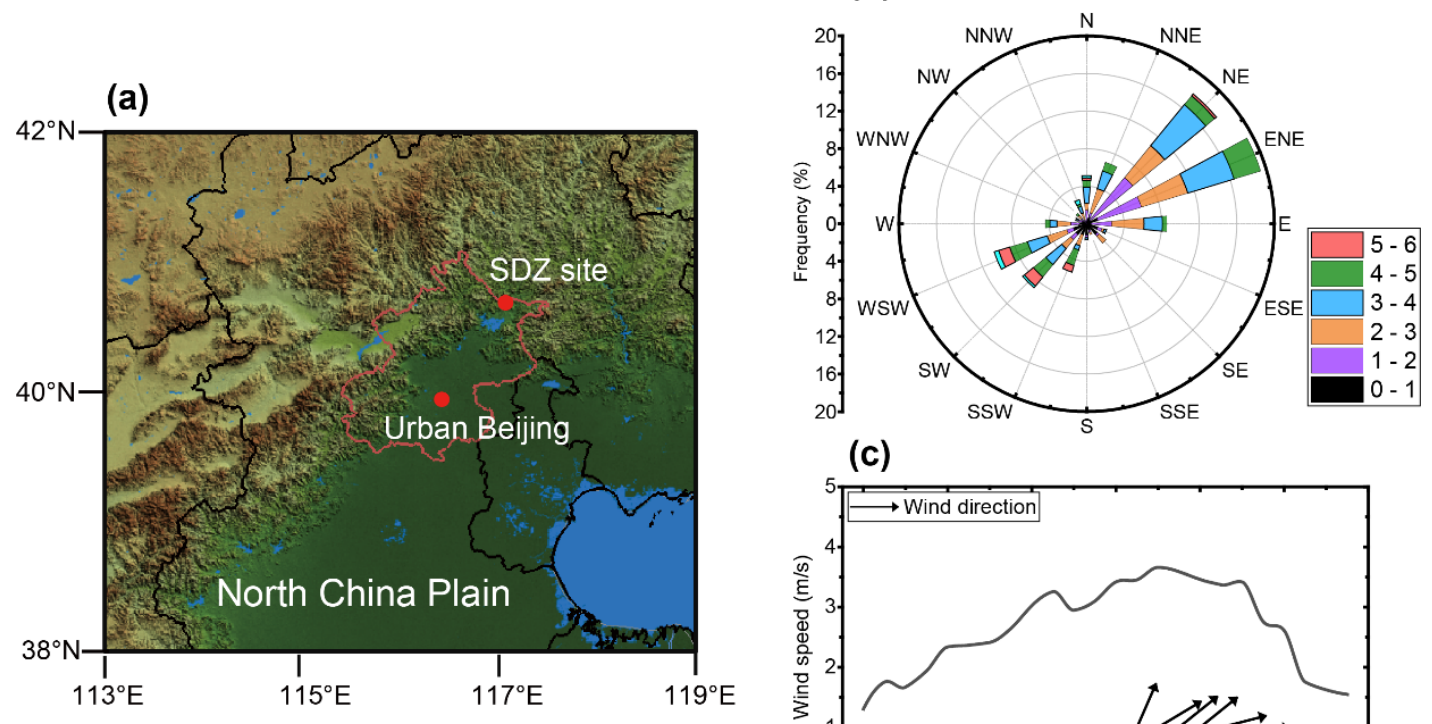

(c)

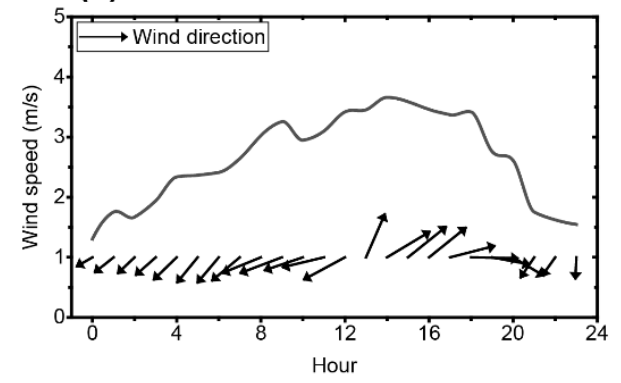

105 Figure 1. (a) Locations of the SDZ site, urban Beijing and North China Plain. (b) Wind frequencies (\%) and (c) diurnal wind variations averaged during the observation period at the SDZ site.

\subsection{Instruments and measurements}

The detailed information of the instruments used in this study has been summarized in Table S1. PAN concentration is measured with an online gas chromatograph equipped with an electron capture detector (GC-ECD). The capillary column is mounted in a compact temperature-controlled oven whose temperature is fixed at $12^{\circ} \mathrm{C}$. The ECD temperature is maintained at $50^{\circ} \mathrm{C} \pm 0.2^{\circ} \mathrm{C}$. The time resolution is 5 minutes, and the detection limit is 20 ppt. More information about the configuration of this instrument has been presented in our previous work (Qiu et al., 2020a). A regular calibration check was conducted every month to guarantee the quality of the PAN results since August 2015, usually on a day with low PAN concentration.

115 The proton transfer reaction-time of flight-mass spectrometer (PTR-ToF-MS) is used to measure concentrations of $\mathrm{HCHO}, \mathrm{CH}_{3} \mathrm{CHO}$, acetone, propene $\left(\mathrm{C}_{3} \mathrm{H}_{6}\right)$ and isoprene. To obtain a higher signal/noise ratio of the VOC species, all mass spectra are stored at a relatively low time resolution of one hour. Detailed descriptions of the PTR-ToF-MS configuration 
and calibration methods are listed in Sheng et al. (2018). HONO measurements are carried out using a long-path absorption photometer (LOPAP-03, QUMA). The HONO gas is collected in the atmosphere and then absorbed by solutions. The sampling rates of gas flow and liquid flow are set to $1.3 \mathrm{~L} \mathrm{~min}^{-1}$ and $0.30-0.34 \mathrm{~mL} \mathrm{~min}^{-1}$, respectively. We also calibrated the LOPAP instrument every week to guarantee data quality during the observation period.

Online measurements of $\mathrm{O}_{3}, \mathrm{NO}_{\mathrm{x}}, \mathrm{PM}_{2.5}$, and $\mathrm{CO}$ are also conducted using a $\mathrm{UV}$ photometric $\mathrm{O}_{3}$ analyzer (model 49i, Thermo Electron Corporation, USA), a $\mathrm{NO}_{\mathrm{x}}$ analyzer (model 42i, Thermo Electron Corporation, USA), a TEOM-1405 analyzer, and a cavity ring-down spectrometer (G2401, Picarro, Inc., USA), respectively. Photolysis rates (J), including $J\left(\mathrm{O}^{1} \mathrm{D}\right), J(\mathrm{HCHO})$, and $J(\mathrm{HONO})$ are simultaneously measured by the PFS-100 Photolysis Rate Analyzer (Focused Photonics Inc., China). The analyzer receives solar radiation with a quartz probe and transfers the radiation to the spectrum via optical quartz fibers. The spectrum data is evaluated and compared with reference data via a mathematical approach to obtain the photolytic rate.

\subsection{Other data}

As the SDZ site is also a national meteorology observatory, meteorological variables, including temperature (T), relative humidity (RH), sea level pressure (SLP), wind direction and speed, were continuously measured during the observation period. In addition, we use hourly European Centre for Medium-Range Weather Forecasts Reanalysis v5 (ERA5) data $\left(0.25^{\circ} \times 0.25^{\circ}\right)$ to assess the impact of atmospheric circulation on pollutant levels at the SDZ site. The ERA5 data are accessed from https://cds.climate.copernicus.eu/. In addition, concentrations of $\mathrm{O}_{\mathrm{x}}\left(\mathrm{O}_{3}+\mathrm{NO}_{2}\right)$ obtained from the Beijing Municipal Ecological and Environmental Monitoring Center (http://www.bjmemc.com.cn/) are also utilized. Here, we average the mixing ratios over 8 stations in the urban region and at the MiYunshuiku (MY) site to represent the $\mathrm{O}_{\mathrm{x}}$ levels in urban region and rural region near SDZ.

\section{Results}

\subsection{High PAN levels during haze events in autumn}

Figure 2a shows the temporal variations in PAN and related atmospheric components at the SDZ site from 10/13 to 10/27, 2020. The mean concentrations of $\mathrm{PAN}, \mathrm{PM}_{2.5}, \mathrm{O}_{3}, \mathrm{NO}_{x}, \mathrm{HCHO}, \mathrm{HONO}, \mathrm{CH}_{3} \mathrm{CHO}$ and $\mathrm{C}_{3} \mathrm{H}_{6}$ are $1.11 \pm 0.88 \mathrm{ppb}$, $34.2 \pm 23.8 \mu \mathrm{g} \mathrm{m}^{-3}$, 27.6 $\pm 14.5 \mathrm{ppb}, 8.5 \pm 2.8 \mathrm{ppb}, 4.9 \pm 3.9 \mathrm{ppb}, 0.15 \pm 0.16 \mathrm{ppb}, 1.6 \pm .1 .1 \mathrm{ppb}$, and $0.7 \pm 0.5 \mathrm{ppb}$, respectively. Compared with recent studies in China (Table S2), the observed PAN concentration during autumn at the SDZ site is generally lower than PAN levels over the urban NCP (Zhang et al., 2017; Liu et al., 2018) and in southwestern China (Sun et al., 2020) but comparable to those in the suburban NCP region (Qiu et al., 2019a; Zhang et al., 2019). In addition, the PAN level at the SDZ site is remarkably higher than those obtained from the southern coastal region (Zhu et al., 2018; Zeng et al., 2019a; Hu et al., 2020) and Tibet (Xu et al., 2018), implying a severe photochemical pollution level over the NCP on a regional scale. 

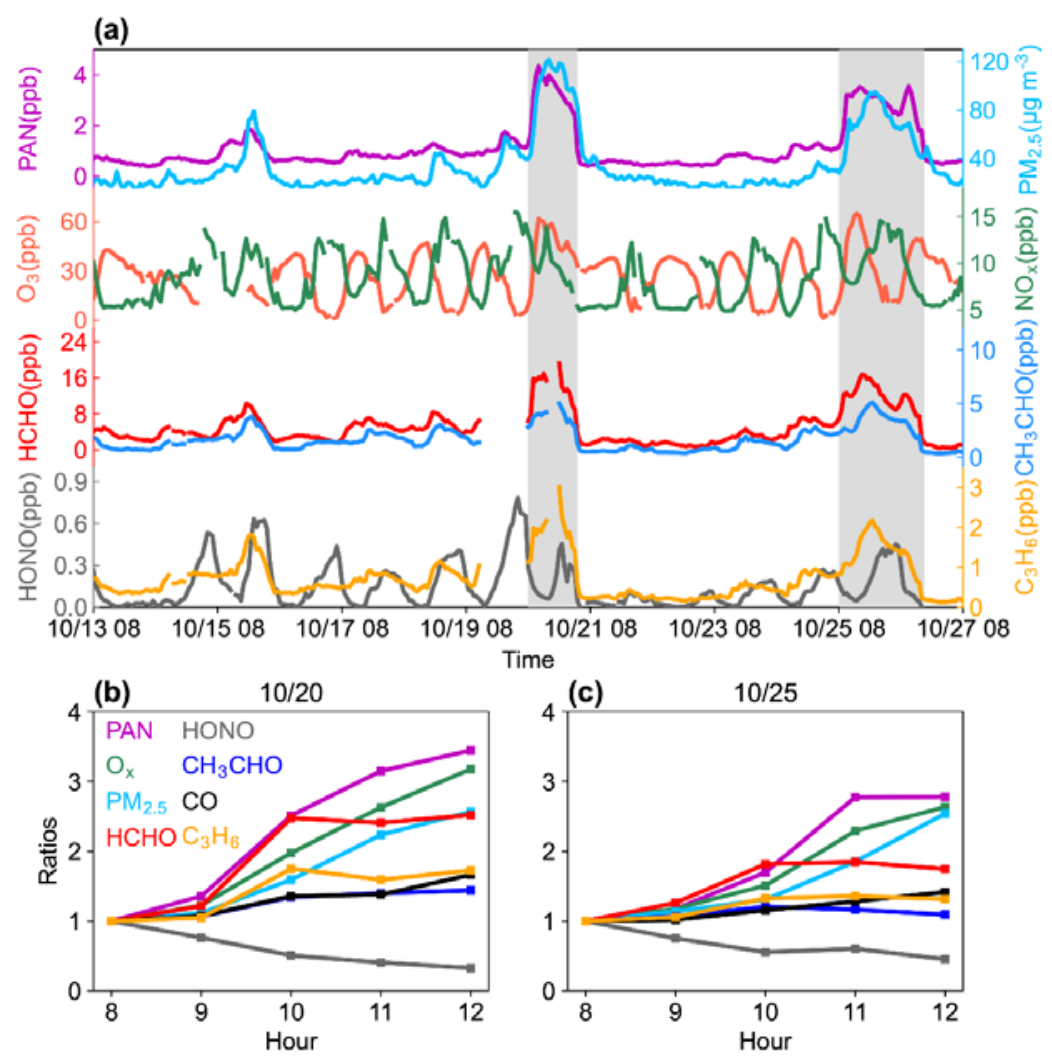

Figure 2. (a) Observed hourly concentrations of PAN (ppb), $\mathrm{PM}_{2.5}\left(\mu \mathrm{g} \mathrm{m} \mathrm{m}^{-3}\right), \mathrm{O}_{3}(\mathrm{ppb}), \mathrm{NO}_{\mathrm{x}}(\mathrm{ppb}), \mathrm{HCHO}(\mathrm{ppb}), \mathrm{CH} \mathrm{CHO}(\mathrm{ppb})$, HONO (ppb) and $\mathrm{C}_{3} \mathrm{H}_{6}(\mathrm{ppb})$ at the SDZ site from 10/13 to 10/27, 2020. The shades denote the days when hourly PAN concentrations exceed $3 \mathrm{ppb}$. (b-c) Ratios of atmospheric constituent concentrations to the concentrations at 8:00 a.m. on the mornings of 10/20 and 10/25 when abrupt PAN growths occur.

We find two pollution events (10/20 and 10/25-10/26) occurring at the SDZ site with hourly PAN concentrations in excess of $3 \mathrm{ppb}$ (Figure 2a). Meanwhile, daytime $\mathrm{O}_{3}$ concentrations during the two pollution episodes were 16-39\% higher than those on clean days (Table 1). Similar increase was also found in $\mathrm{PM}_{2.5}$, which was strongly correlated with PAN with a correlation coefficient $(R)$ of 0.9 during the observation period. Daily mean $\mathrm{NO}_{\mathrm{x}}$ concentrations on pollution days were $16-$ 42\% higher than clean days as shown in Table 1, implying the potential role of regional transport under unfavorable meteorological conditions. Abrupt increases of PAN and related pollutants could be confirmed on the mornings of 10/20 and 10/25. Figure 2b-c display the ratios of individual component concentrations to their concentrations at 8:00 a.m. on the two pollution days. In general, PAN concentrations exhibited fast growth rates by $244 \%$ and $178 \%$ over the morning hours (8:00-12:00) of 10/20 and 10/25, which were 10.6 and 7.7 times those during clean days. These increase rates are highest among all species illustrated in Figure 2b-c. The corresponding growth rates of 9-44\% for PAN's primary precursor $\mathrm{CH}_{3} \mathrm{CHO}$ and $41-66 \%$ for chemically inert $\mathrm{CO}$ are much lower than upsurge of PAN. This result suggests the potential 
enhanced local photochemistry at the SDZ site on pollution days during autumn despite reduction in observed photolysis rate due to aerosol and cloud radiative effects.

Table 1. Statistical results of concentrations for PAN (ppb), $\mathrm{PM}_{2.5}\left(\mu \mathrm{g} \mathrm{m} \mathrm{m}^{-3}\right), \mathrm{O}_{3}(\mathrm{ppb}), \mathrm{NO}_{\mathrm{x}}(\mathrm{ppb}), \mathrm{HCHO}(\mathrm{ppb}), \mathrm{CH} 3 \mathrm{CHO}(\mathrm{ppb})$, $\mathrm{C}_{3} \mathrm{H}_{6}(\mathrm{ppb})$ and HONO (ppb) on average, during clean days and pollutions days. The clean days represent the time excluding the pollution days (10/20 and 10/25-10/26), and the daytime denotes 8:00-19:00.

\begin{tabular}{cccccc}
\hline Species & Mean & Clean & \multicolumn{3}{c}{ Pollution } \\
\hline & & & $10 / 20$ & $10 / 25$ & $10 / 26$ \\
\hline PAN (ppb) & $1.11 \pm 0.88$ & $0.77 \pm 0.35$ & $2.67 \pm 1.17$ & $2.33 \pm 1.06$ & $2.09 \pm 1.06$ \\
Daytime PAN & $1.22 \pm 0.99$ & $0.79 \pm 0.25$ & $3.41 \pm 0.95$ & $2.85 \pm 0.85$ & $2.17 \pm 1.07$ \\
$\mathrm{O}_{3}(\mathrm{ppb})$ & $27.6 \pm 14.5$ & $26.2 \pm 12.2$ & $34.6 \pm 22.2$ & $31.8 \pm 22.5$ & $31.0 \pm 14.0$ \\
Daytime O3 & $36.1 \pm 11.5$ & $33.7 \pm 8.4$ & $46.7 \pm 17.9$ & $46.8 \pm 18.0$ & $39.1 \pm 10.9$ \\
$\left.\mathrm{PM}_{2.5}(\mu \mathrm{g} \mathrm{m})^{-3}\right)$ & $34.2 \pm 23.8$ & $25.7 \pm 12.9$ & $81.5 \pm 33.2$ & $57.2 \pm 25.7$ & $57.2 \pm 18.5$ \\
$\mathrm{NO}_{\mathbf{x}}(\mathrm{ppb})$ & $8.47 \pm 2.80$ & $7.93 \pm 2.54$ & $11.3 \pm 2.31$ & $10.8 \pm 4.35$ & $9.24 \pm 3.58$ \\
$\mathrm{HCHO}_{(\mathrm{ppb})}$ & $4.86 \pm 3.88$ & $3.63 \pm 2.19$ & $14.1 \pm 3.67$ & $10.9 \pm 4.35$ & $7.21 \pm 4.62$ \\
$\mathrm{CH}_{3} \mathrm{CHO}(\mathrm{ppb})$ & $1.61 \pm 1.09$ & $1.31 \pm 0.75$ & $3.87 \pm 0.61$ & $3.09 \pm 1.09$ & $2.26 \pm 1.45$ \\
$\mathrm{C}_{3} \mathrm{H}_{6}(\mathrm{ppb})$ & $0.70 \pm 0.50$ & $0.56 \pm 0.33$ & $1.94 \pm 0.49$ & $1.28 \pm 0.52$ & $0.94 \pm 0.62$ \\
$\mathrm{HONO}_{(\mathrm{ppb})}$ & $0.15 \pm 0.16$ & $0.13 \pm 0.14$ & $0.34 \pm 0.25$ & $0.17 \pm 0.09$ & $0.25 \pm 0.17$
\end{tabular}

Previous studies also reported rapid increases of PAN accompanied with $\mathrm{PM}_{2.5}$ enhancement during cold seasons over the NCP region (Liu et al., 2018; Zhang et al., 2019). For example, Zhang et al., (2019) showed that PAN concentration was doubled at noon during a haze episode at a suburban site in Beijing in comparison with that in the morning, and the synchronous increases of $\mathrm{PM}_{2.5}$ and $\mathrm{O}_{3}$ concentrations were also found. Liu et al. (2018) also reported rapid growth of PAN during a wintertime pollution event in urban Jinan along with high $\mathrm{PM}_{2.5}$ concentration; however, they showed rather lower $\mathrm{O}_{3}$ concentration during winter haze days because of high $\mathrm{NO}_{\mathrm{x}}$ concentrations and intense NO titration effects in the urban region. Therefore, synchronous increases of PAN and $\mathrm{PM}_{2.5}$ can occur over the whole NCP region during cold days, while co-occurrence of $\mathrm{O}_{3}$ enhancement just exits in suburban and background regions where $\mathrm{NO}_{\mathrm{x}}$ emissions are rather low.

\subsection{Meteorological conditions}

On synoptic scale, PAN mixing ratios are largely influenced by meteorological conditions. Figure 3 shows the atmospheric circulation for clean days and two pollution days (10/20 and 10/25), focusing on variations of SLP and wind in the boundary layer. During the observation period, the SDZ site was affected by a high-pressure system in the west 185 associated with northwesterly. Similar weather pattern was also identified on clean days, facilitating pollutant diffusion. During the two pollution days, southwesterly prevailed over the NCP. On 10/20, the SDZ site was in the south of a strong low-pressure system, leading to southwesterly resulted from pressure gradient force. The southwesterly on 10/25 was caused 
by a weak high-pressure system with anticyclone in the southeast. The prevailing southwesterlies could be conducive to pollution accumulation in Beijing and transport to the rural SDZ site in the north.

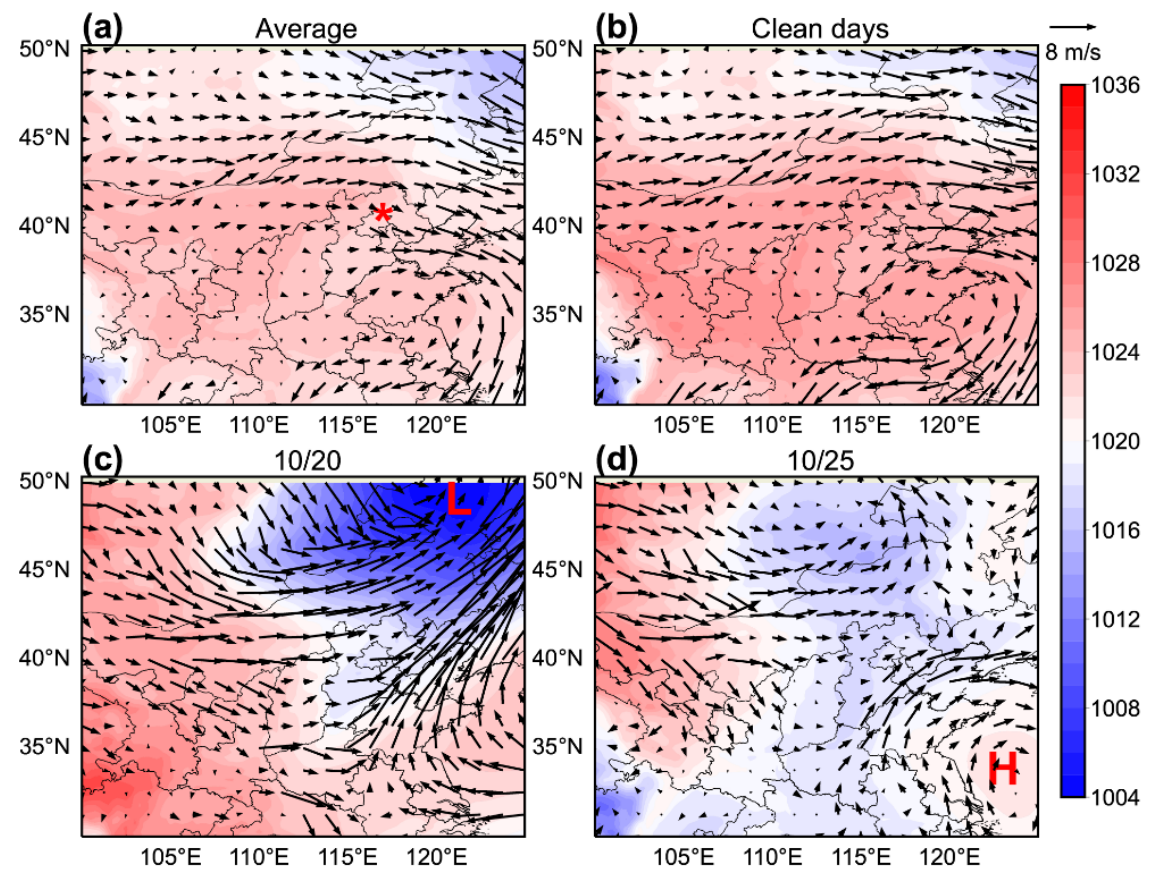

Figure 3. Wind at $925 \mathrm{hPa}$ and sea level pressure (hPa) derived from ERA5 (a) averaged during 10/13-10/27, (b) clean days and on (c) 10/20 and (d) 10/25. The red asterisk in (a) shows the location of the SDZ site.

Temporal variations of observed meteorological variables during the observation period at the SDZ site are shown in

195 Figure 4 a-e. The daytime T, RH, SLP, $J\left(\mathrm{O}^{1} \mathrm{D}\right)$ and meridian wind speed $(\mathrm{V})$ near the surface are also compared between clean days and pollution days, illustrated as boxplots in Figure 4f-j. We find positive daytime T and RH anomalies on 10/20 and 10/25, indicating hot and wet weather conditions. Although higher temperature can promote thermal decomposition of PAN, it also accelerates photochemistry thus increases PAN mixing ratios. Higher RH has been proved to inhibit heterogeneous reactions of PAN on soot, leading to increase of PAN concentration in the atmosphere (Zhao et al., 2017).

200 Negative SLP anomalies and positive V anomalies on 10/20 and 10/25 could contribute to pollution accumulation and transport to the north, coinciding with the ERA5 results shown in Figure 3. $J\left(\mathrm{O}^{1} \mathrm{D}\right)$ was reduced by $20-34 \%$ on the two pollution days due to aerosol and cloud radiative effects, which was unfavorable for photochemistry. As noted above, we can conclude that the meteorological conditions during pollution events are virtually conducive to formation and accumulation of PAN at the SDZ site, though reductions are identified in photolysis rates. 

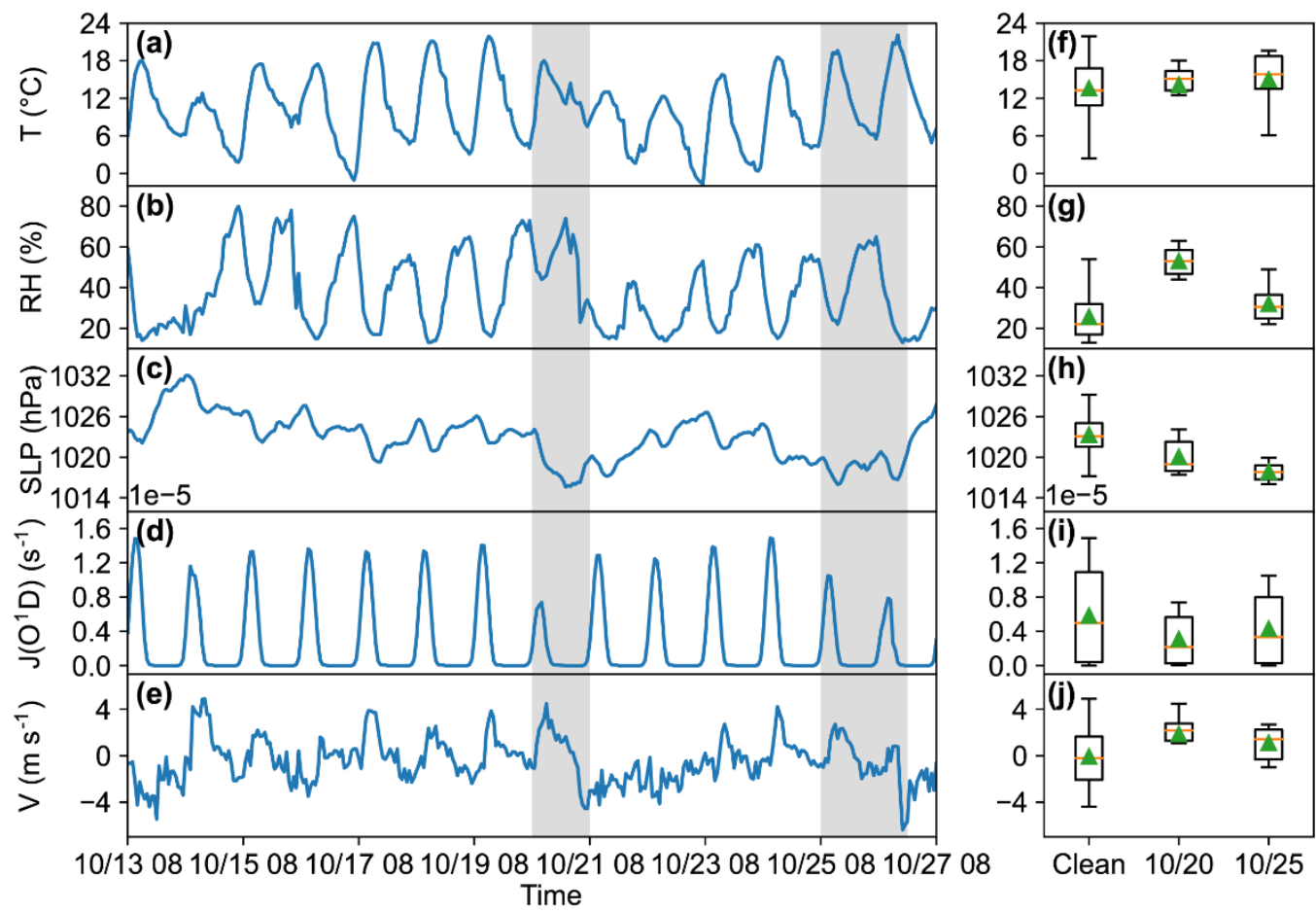

Figure 4. (a-e) Time series of observed temperature $\left(\mathrm{T} ;{ }^{\circ} \mathrm{C}\right)$, relative humidity (RH; \%), sea level pressure (SLP; hPa), photolysis rate for $\mathrm{O}_{3}\left(\mathrm{~J}\left(\mathrm{O}^{1} \mathrm{D}\right)\right.$; $\left.\mathrm{s}^{-1}\right)$ and meridional wind speed $\left(\mathrm{V} ; \mathrm{m} \mathrm{s}^{-1}\right)$ during $10 / 13-10 / 27$ at the SDZ site. The shades denote the pollution days. (f-j) Box plots for daytime meteorological parameters during clean days and two pollution days. The red lines and green triangles denote the median and mean values, respectively.

\subsection{Strong local photochemistry at the SDZ site}

As the SDZ site is a clean background station with scarce anthropogenic sources, the abrupt increases in PAN and other secondary pollutants on 10/20 and 10/25 were preliminarily supposed in relation to pollutant transport from the urban region. However, the increases of PAN on pollution days impossibly caused by direct PAN transport from the urban region, though its relatively long thermal lifetime during the observation period ( 1 day). Here, direct transport impact is restricted to PAN that has been formed in other regions, but exclusive of PAN precursors. Figure 5a-c shows the temporal variations of daytime PAN and $\mathrm{O}_{\mathrm{x}}$ at the urban, SDZ and MY site on the two pollution days when abrupt increases of PAN occurred. The detailed locations of the three sites and distances between them are shown in Figure 5d. In the conventional view, southern wind facilitates pollutant transport from the urban region to the SDZ site. On 10/20, the PAN concentrations at the SDZ site increased from 1.3ppb at 8:00 a.m. to $4.3 \mathrm{ppb}$ at 12:00 a.m. However, the prevailing wind turned to southerlies until 10:00 a.m. (Figure 5a). The growth time of PAN due to direct transport from the southern region was too short. The calculated transport distance was just about $26 \mathrm{~km}$ during 10:00-12:00 a.m. when observed southern wind speed was 1.2-3.4 m/s. It is 
approximately the distance between the SDZ site and the MY site, another rural site near the Miyun Reservoir (Figure 5d). The $\mathrm{O}_{\mathrm{x}}$ concentration at the MY site during 9:00-12:00 a.m. of 10/20 was slightly lower than that at the SDZ site (Figure 5c), implying the similar photochemical pollution level at the two sites. Consequently, despite the observed high PAN concentration at the urban site (Figure 5a), the abrupt increase of PAN on the morning of 10/20 was not likely caused by direct PAN regional transport. On another pollution day of 10/25, the prevailing wind turned to southerlies after 12:00 a.m. Direct PAN transport from urban region could not explain the fast PAN growth in the morning. In addition, we also exclude possible impact of PBL evolution in the morning on increases of PAN, because our previous observation in an urban city of the NCP region reported that nighttime PAN concentration in boundary layer was just $9.5 \%$ higher than surface-layer PAN concentration (Qiu et al., 2019a). The slightly higher PAN concentration in upper layer could not be the cause of rapid increases of PAN on the mornings of pollution days.
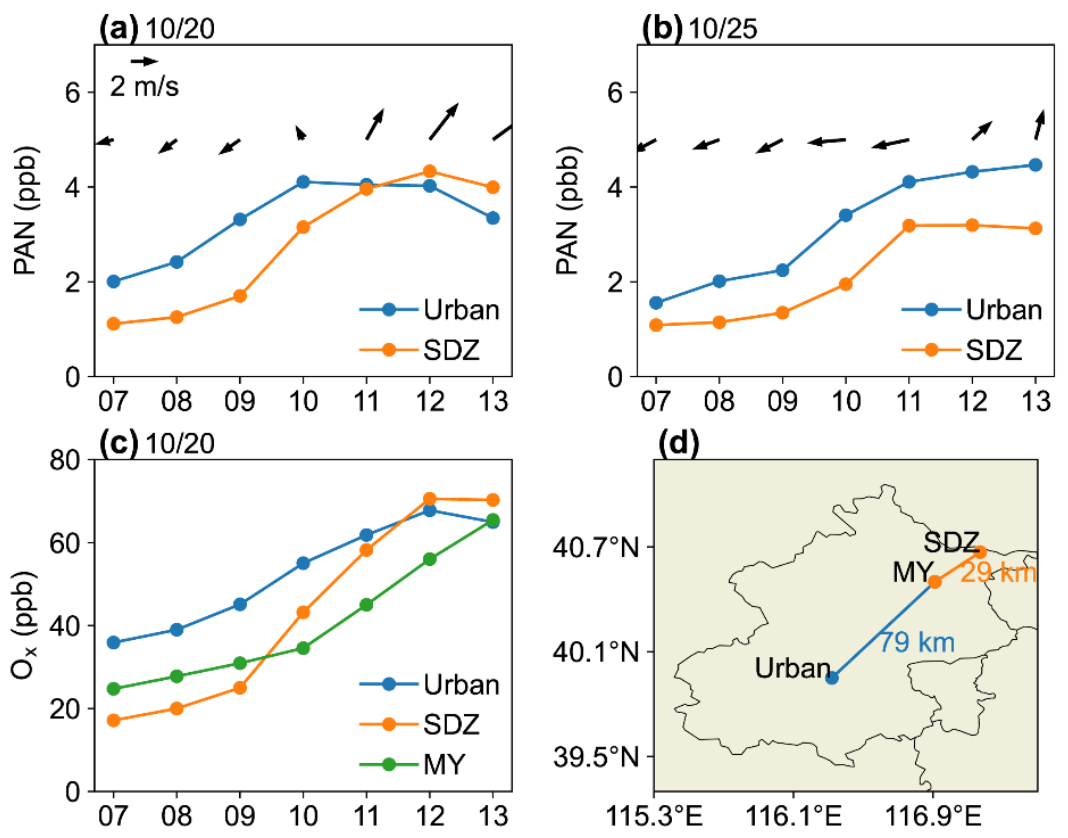

Figure 5. Hourly variations of PAN concentrations (ppb) and $10 \mathrm{~m}$ wind at the urban and SDZ site during 7:00-13:00 on (a) 10/20 and (b) 10/25. (c) Hourly variation of $O_{x}$ concentrations (ppb) at the urban, SDZ and MY site during 7:00-13:00 on 10/20. (d)

Detailed locations of the urban, SDZ and MY site and the distances between them.

To quantitatively assess the impacts of regional transport and local photochemistry on PAN levels at the SDZ site, we choose $\mathrm{CO}$ as a tracer. $\mathrm{CO}$ is chemically inert and greatly affected by anthropogenic sources, thus it can well represent the physical transport of pollutants from the urban region (Gao et al. 2005; Worden et al., 2013; Chen et al., 2020). Detailed calculation method has been described in Method S1. It should be noted that the calculation of physical transport impact aims at PAN that has been formed outside of the SDZ site. Figure 6 displays the process diagnostic results of PAN at the 
SDZ site. The positive PAN change rate (Chem + Phys) was only found in the morning (8:00-12:00), which was attributed to the high net chemical production rate (Chem) with a value of $0.14 \mathrm{ppb} \mathrm{h}^{-1}$. In the afternoon (12:00-16:00) and evening (16:00-20:00), regional transport (Phys) by southwesterlies contributed to increases in PAN with rates of $0.05 \mathrm{ppb} \mathrm{h}^{-1}$ and $0.02 \mathrm{ppb} \mathrm{h}^{-1}$, respectively. However, the negative net chemical production rates $\left(-0.07 \mathrm{ppb} \mathrm{h}^{-1}\right.$ and $\left.-0.06 \mathrm{ppb} \mathrm{h}^{-1}\right)$ originating from strong thermal loss rates (L[PAN], $-0.57 \mathrm{ppb} \mathrm{h}^{-1}$ and $-0.34 \mathrm{ppb} \mathrm{h}^{-1}$ ) completely overcome the PAN increases from transport. This evidence manifests local photochemical formation of PAN in the morning, coinciding with PAN's diurnal variation. The impacts of photochemistry and regional transport on PAN were both largely enhanced during pollution days (Figure 6 and Figure S1). The net chemical formation rate (Chem) was $0.45 \mathrm{ppb} \mathrm{h}^{-1}$ on the morning of pollution days, which was 6.3 times that on clean days. This again demonstrates that strong local photochemical reactions contributed most to PAN enhancement on the mornings of the two pollution days instead of direct transport.

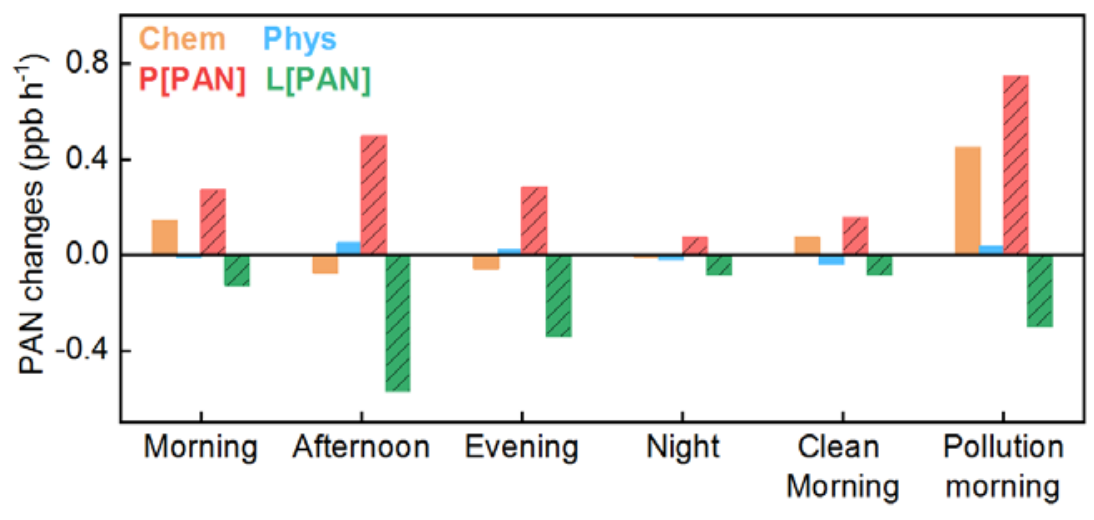

Figure 6. Process diagnostic analysis of PAN on average and on the mornings of clean and pollution days. Chem, Phys, P[PAN], and L[PAN] denote the net chemical production, physical changes, chemical production and loss rates of PAN, respectively. Morning, afternoon, evening and night correspond to 8:00-12:00, 12:00-16:00, 16:00-20:00 and 20:00-08:00, respectively.

\subsection{Impacts of precursors on rapid increase of PAN}

A key question in explaining the abrupt increase of PAN at the SDZ site is how its precursors change. PAN is directly formed through the reaction between $\mathrm{PA}$ radical and $\mathrm{NO}_{2}$. As $\mathrm{NO}_{2}$ is much more abundant than PAN in the atmosphere, PA formation through VOC oxidation and photolysis may have greater impacts on PAN. As noted above, the dominant three pathways of PA formation are through direct oxidation of $\mathrm{CH}_{3} \mathrm{CHO}$, photolysis of acetone and methylglyoxal (MGLY) (Fischer et al., 2014). Figure 7 displays the calculated PA production rates through these three pathways. The PA production through $\mathrm{CH}_{3} \mathrm{CHO}+\mathrm{OH}$ is calculated by $k \times\left[\mathrm{CH}_{3} \mathrm{CHO}\right] \times[\mathrm{OH}]$, where $k=5.55 \times 10^{-12} \times \exp (311 / \mathrm{T})$ (Seinfeld and Pandis, 2006), the $\mathrm{CH}_{3} \mathrm{CHO}$ concentration is obtained from PTR-ToF-MS measurements, and the $\mathrm{OH}$ concentration is assumed to be with a maximum value of $3.0 \times 10^{6} \mathrm{~cm}^{-3}$ at noon, which is consistent with Lu et al. (2019). The PA production rates through photolysis of acetone and MGLY are calculated by $J$ [acetone] $\times$ [acetone] and $J[$ MGLY] $\times[$ MGLY], where the photolysis 
rates $J$ are estimated using the tropospheric ultraviolet and visible radiation (TUV) model described in Madronich and Flocke (1999). The acetone concentration is collected from PTR-ToF -MS measurements, and the MGLY concentration is obtained from Qiu et al., (2020c) in which the modified modeling MGLY concentration near the SDZ site in autumn of 2018 was about $0.012 \mathrm{ppb}$. As seen in Figure 7, $\mathrm{CH}_{3} \mathrm{CHO}$ oxidation by $\mathrm{OH}$ radical plays a dominant role in PA production at the SDZ site rather than photolysis of acetone and MGLY. This result represents a combination of a relatively lower photolysis rate of acetone $\left(\sim 10^{-7} \mathrm{~s}^{-1}\right)$ and previously reported low MGLY concentration ( $\left.\sim 0.012 \mathrm{ppb}\right)$ during autumn at the rural site (Qiu et al., 2020c). Our results are consistent with previous studies, in which they also confirm the dominant role of $\mathrm{CH}_{3} \mathrm{CHO}+\mathrm{OH}$ in PA formation in eastern China (Zeng et al., 2019a; Zhang et al., 2020b) and even on global scale (Fischer, et al., 2014).

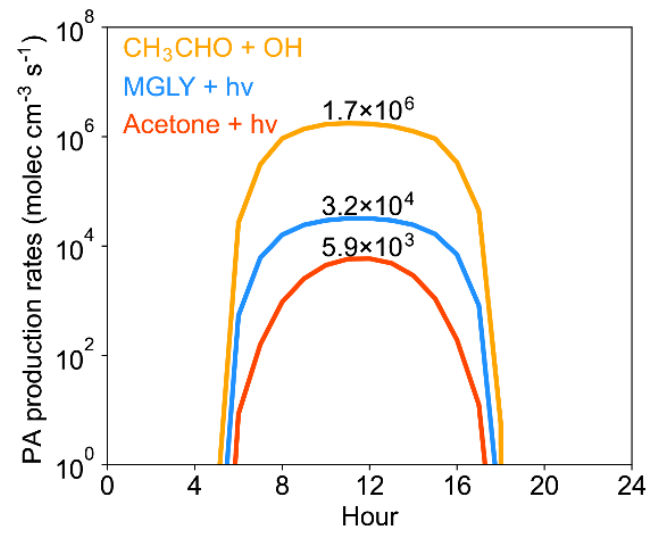

Figure 7. Estimated diurnal variations of $\mathrm{PA}$ production rates $\left(\right.$ molec $\left.\mathrm{cm}^{-3} \mathrm{~s}^{-1}\right)$ through $\mathrm{CH}_{3} \mathrm{CHO}+\mathrm{OH}$, and photolysis of acetone and MGLY averaged during the observation period at the SDZ site. The numbers on the top of the lines denote the maximum values at noon through the three pathways.

$\mathrm{CH}_{3} \mathrm{CHO}$ could be directly emitted to the atmosphere and also formed through oxidations of alkenes, such as $\mathrm{C}_{3} \mathrm{H}_{6}$. Figure 8 shows the daily variations of $\mathrm{CH}_{3} \mathrm{CHO}$ and $\mathrm{C}_{3} \mathrm{H}_{6}$ concentrations at the SDZ site during Case 1 (10/16-10/20) and Case $2(10 / 22-10 / 26)$. Here, we use the data at 8:00 a.m. to represent the VOC concentration level before intense photochemistry during the daytime. On 10/16, the NCP region was influenced by a high-pressure system with northerlies (Figure 4e), which was conducive to pollutant diffusion. From 10/17 to 10/20, persistent stagnant conditions with southerlies during late morning to evening contributed to pollutant accumulation and transport from the urban region, though northerlies prevailed from night to morning. Thus, the $\mathrm{C}_{3} \mathrm{H}_{6}$ and $\mathrm{CH}_{3} \mathrm{CHO}$ concentrations during 10/16 to 10/20 both exhibited increasing trends, demonstrating the cumulative effect. Similar in appearance to that from 10/22 to 10/25 (Figure 8d-e), during which the $\mathrm{C}_{3} \mathrm{H}_{6}$ and $\mathrm{CH}_{3} \mathrm{CHO}$ concentrations increased by $180 \%$ and $196 \%$. These indicate that cumulative effect with persistent stagnant weather conditions elevates the concentration level of PAN precursors, causing high VOC levels before the abrupt increases occurred on the mornings of $10 / 20$ and 10/25. Furthermore, the high $\mathrm{PAN} / \mathrm{NO}_{2}$ ratios on 
10/20 and 10/25 when abrupt increases of PAN appeared (Figure 8c, f, i) also enabled the identification of strong photochemistry with a relatively high precursor level. As shown in Figure 6, the net chemical formation rate on the morning of pollution days was 6.3 times that on clean days. However, the increase ratios for $\mathrm{CH}_{3} \mathrm{CHO}$ and $\mathrm{C}_{3} \mathrm{H}_{6}$ were just about 2.8 times higher than clean days (Figure 8g-h). That is to say, increase of VOC concentration could not fully explain the abrupt increase of PAN, although it indeed promoted the photochemical formation of PAN during the two pollution events.
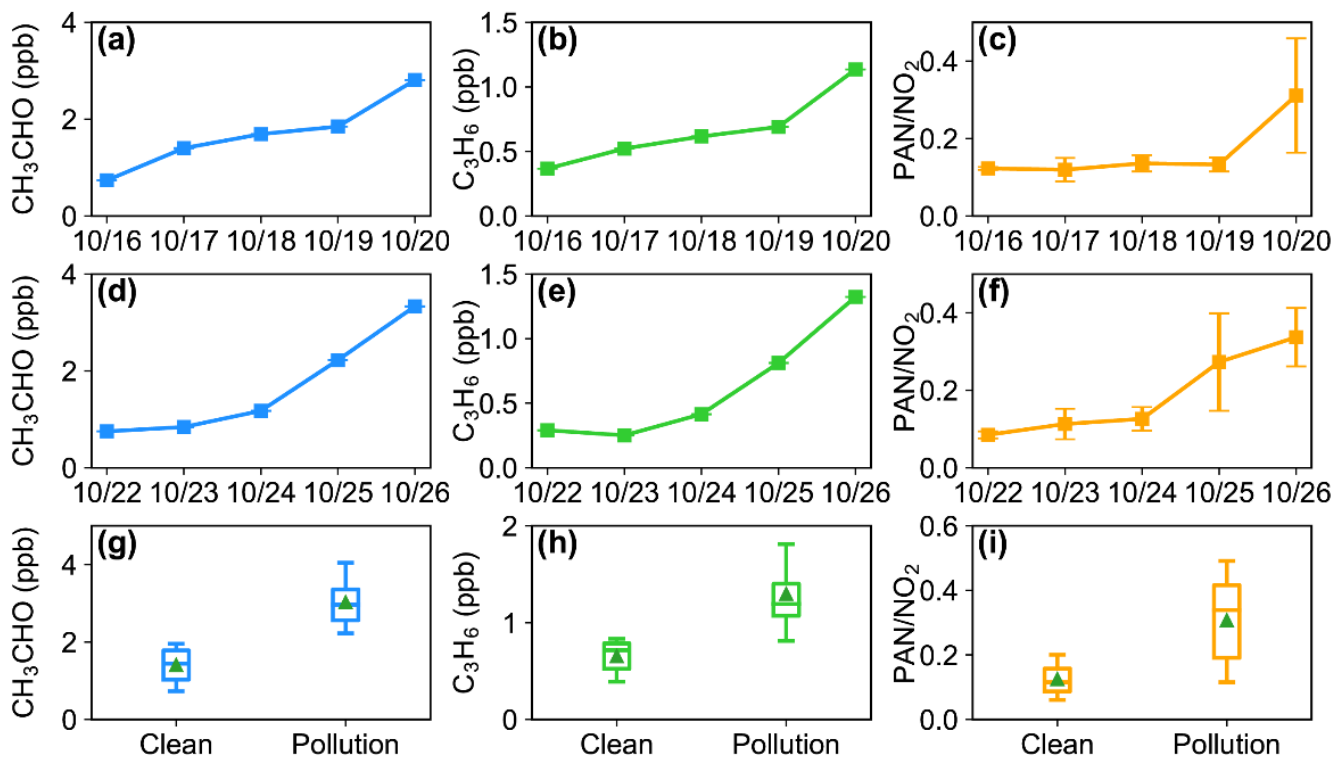

Figure 8. Observed concentrations of $\mathrm{CH}_{3} \mathrm{CHO}$ (ppb), $\mathrm{C}_{3} \mathrm{H}_{6}$ (ppb) and $\mathrm{PAN} / \mathrm{NO}_{2}$ ratios at 8:00 a.m. (a-c) during Case 1 $(10 / 16-10 / 20)$ and (d-f) Case $2(10 / 22-10 / 26)$ at the SDZ site. Comparisons between concentrations of $\mathrm{CH}_{3} \mathrm{CHO}_{3} \mathrm{C}_{3} \mathrm{H}_{6}$ and

$\mathrm{PAN} / \mathrm{NO}_{2}$ ratios on the mornings of clean days and pollution days.

\subsection{Impacts of radicals on rapid increase of PAN}

In addition to VOC precursors, the observed strong chemical formation on the mornings of pollution days could also relate to enhanced $\mathrm{OH}$ concentration level and atmospheric oxidation capacity. Photolysis of $\mathrm{HONO}, \mathrm{HCHO}$, and $\mathrm{O}_{3}$ can provide the major source of $\mathrm{HO}_{\mathrm{x}}$ radicals (Schnell et al., 2009; Edwards et al., 2014; Tan et al., 2018; Li et al., 2021). Here,

we present the observed time series of $\mathrm{HO}_{x}$ production through photolysis of $\mathrm{HONO}, \mathrm{HCHO}$, and $\mathrm{O}_{3}$ using comprehensive measurements over the rural NCP (Figure 9). The calculation method has been described in Method S2. Unlike HONO and $\mathrm{O}_{3}$, photolysis of $\mathrm{HCHO}$ directly produces $\mathrm{HO}_{2}$. Recycling of $\mathrm{HO}_{2}+\mathrm{NO}$ contributes to $\mathrm{OH}$ formation and $\mathrm{HO}_{2}+\mathrm{HO}_{2}$ consumes $\mathrm{HO}_{2}$ in the atmosphere. The remarkably higher production rate of $\mathrm{NO}+\mathrm{HO}_{2}$ than $\mathrm{HO}_{2}+\mathrm{HO}_{2}($ Table S3) during the observation period at the SDZ site reveals the fast production of $\mathrm{OH}$ through immediate reaction of $\mathrm{NO}+\mathrm{HO}_{2}$. Thus, we use $\mathrm{HO}_{\mathrm{x}}$ here to represent the $\mathrm{OH}$ level. On average, a maximum $\mathrm{HO}_{\mathrm{x}}$ production rate $\left(\mathrm{P}\left[\mathrm{HO}_{\mathrm{x}}\right]\right)$ of $6.5 \times 10^{6} \mathrm{molec} \mathrm{cm}^{-3} \mathrm{~s}^{-1}$ was observed at noon (Figure 9b). The $\mathrm{P}\left[\mathrm{HO}_{\mathrm{x}}\right]$ could be large during periods of pollutions days (Figure 9a). Figure 10 
compares the $\mathrm{P}\left[\mathrm{HO}_{\mathrm{x}}\right]$ during clean days and pollution days. The $\mathrm{P}\left[\mathrm{HO}_{\mathrm{x}}\right]$ at noon of pollution days $\left(11.0 \times 10^{6} \mathrm{molec}^{-3} \mathrm{~s}^{-1}\right)$ was approximately 2 times that on clean days, implying enhanced atmospheric oxidation capacity.
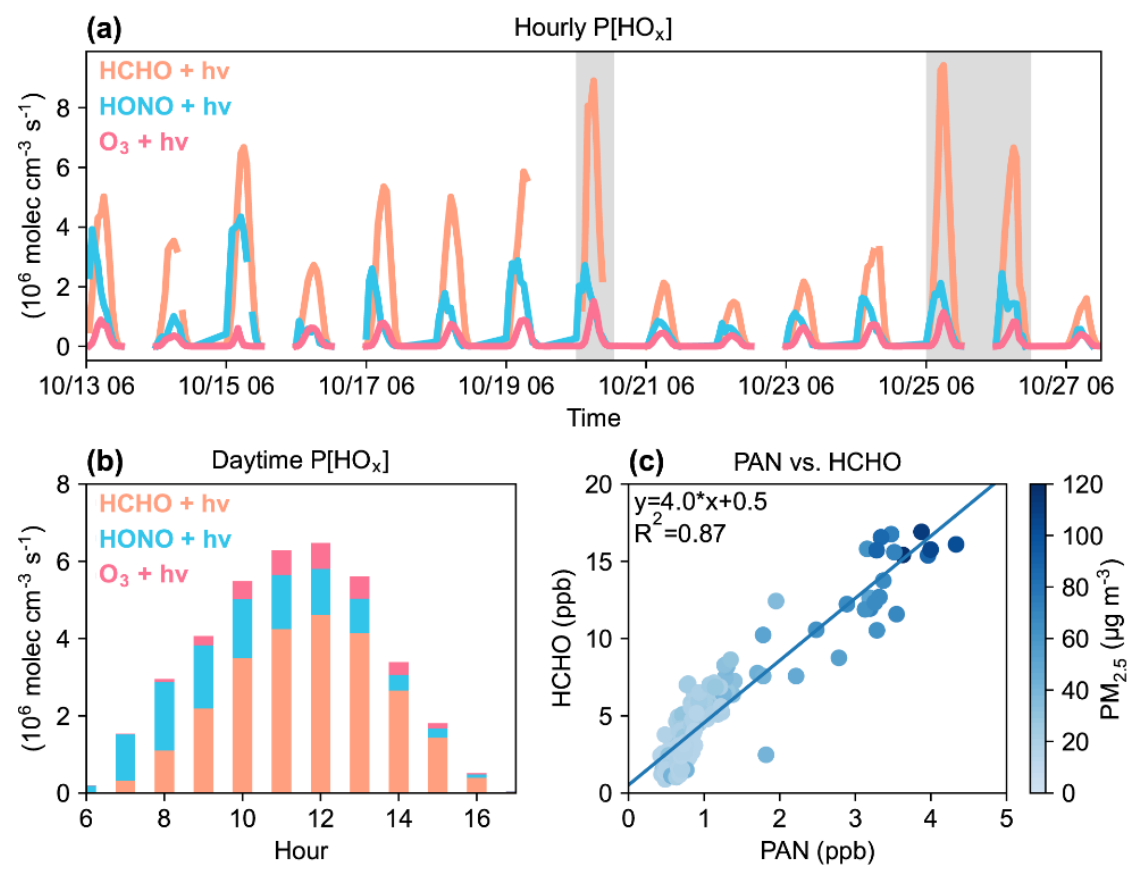

Figure 9. (a) Hourly time series of calculated $\mathrm{HO}_{x}$ production rates $\left(\mathrm{P}\left[\mathrm{HO}_{\mathrm{x}}\right]\right)$ through photolysis of $\mathrm{O}_{3}$, $\mathrm{HONO}$ and $\mathrm{HCHO}$ during 06:00-17:00 from 10/13 to 10/27 at the SDZ site. (b) Daytime P[HOx] through each pathway averaged during 10/13 to 10/27. (c) Daytime PAN concentrations versus HCHO concentrations from 10/13 to 10/27 at the SDZ site. The colors denote the corresponding $\mathbf{P M}_{2.5}$ levels.

In the conventional view, photolysis of $\mathrm{HONO}$ could provide the major source of $\mathrm{OH}$ radical during cold days over the NCP region (Hendrick et al., 2014; Tan et al., 2018). Here we present the observational evidence of the dominant role of HCHO photolysis in daytime $\mathrm{HO}_{x}$ productions during autumn over the rural NCP. Photolysis of HONO was vital in the early morning, but it became less important after 9:00 a.m. due to its fast decomposition with increasing sunlight (Figure 9b). On average, the $\mathrm{P}\left[\mathrm{HO}_{\mathrm{x}}\right]$ through $\mathrm{HCHO}$ photolysis reached $4.6 \times 10^{6}$ molec $\mathrm{cm}^{-3} \mathrm{~s}^{-1}$ at noon, accounting for $71 \%$ among the three pathways (Figure 9b). During pollution days (10/20 and 10/25-10/26), the HCHO photolysis rate reached $8.3 \times 10^{6}$ molec $\mathrm{cm}^{-3} \mathrm{~s}^{-1}$ at noon, which was $140 \%$ higher than that on clean days (Figure 10). Moreover, PAN was strongly correlated with HCHO $\left(R^{2}=0.87\right)$ (Figure 9c). It proves the similar source of PAN and HCHO, also demonstrates a potential impact of HCHO photolysis on PAN increase at this rural site with accelerated photochemistry. The sources of $\mathrm{HO}_{\mathrm{x}}$ radical during cold days have been a subject of recent interest in the field of atmospheric chemistry over the NCP region (Tan et al., 2018; Xue et al., 2020), and most of them reported the importance of HONO in OH radical and atmospheric oxidation capacity during cold days over the NCP. By comparisons, our results at the SDZ site presents a much lower HONO concentration (average: 
$0.15 \mathrm{ppb}$ ) than Tan et al. (2018) and Xue et al. (2020). As the SDZ site is located in the north border of the NCP region, which is much cleaner than the suburban and rural site in Tan et al. (2018) and Xue et al. (2020), then less affected by shortlive species, such as $\mathrm{NO}_{\mathrm{x}}$ and HONO. For another, Tan et al. (2018) and Xue et al. (2020) conducted measurements during 2016-2017 with HONO concentrations of 0.05-0.98 ppb and $1.8 \mathrm{ppb}$, while our results was based on observations in autumn of 2020. The decreasing trend of $\mathrm{NO}_{\mathrm{x}}$ emissions during 2016-2020 due to strict air pollution control measures may contribute to observed lower HONO concentration at present.
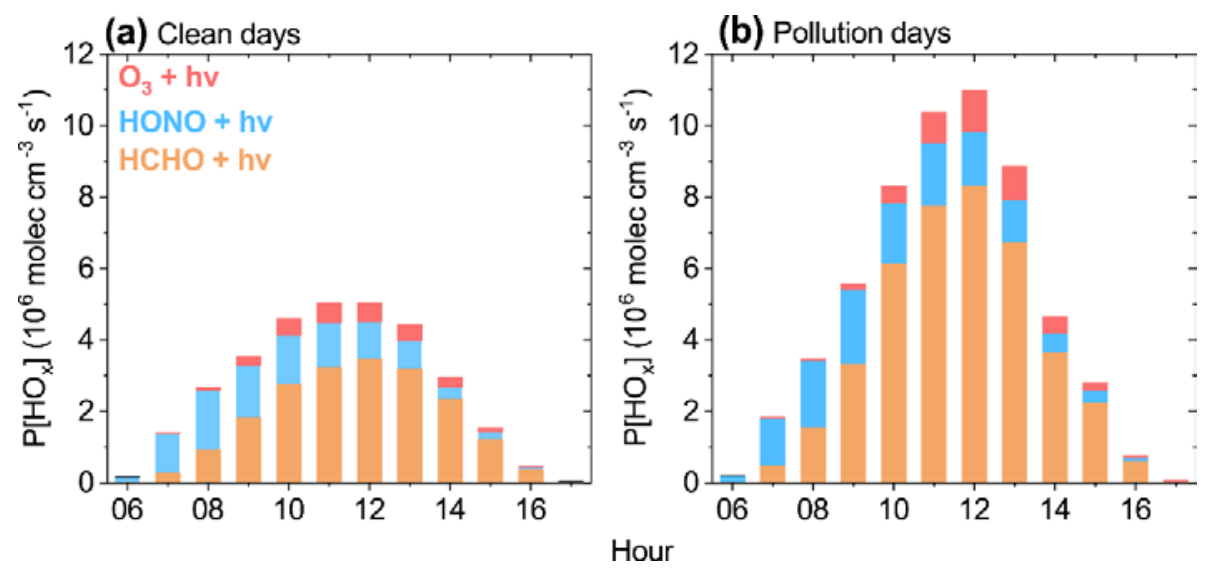

Figure 10. Diurnal variations of $\mathrm{P}\left[\mathrm{HO}_{\mathrm{x}}\right]$ through three pathways during the daytime of clean days (a) and pollution days $(\mathrm{b}, 10 / 22$, $10 / 25$ and 10/26) at the SDZ site.

The source of HCHO at the SDZ site can be largely affected by aged air mass from the urban NCP region instead of biogenic source because the observed mean concentration of isoprene during pollution days was relatively low (0.2 ppb). As shown in Table S4, the observed mean HCHO concentration of $4.6 \pm 3.8 \mathrm{ppb}$ at the SDZ site is lower than most of observations in urban and suburban Beijing (3.2-29.2 ppb) (Pang et al., 2009; Duan et al., 2012; Zhang et al., 2012; Rao et al., 2016; Sheng et al., 2018; Yang et al., 2018; Qian et al., 2019; Zhou et al., 2019) and urban Guangzhou in summer (7.6 ppb) (Ling et al., 2017). But it is slightly higher than most observations in other southern China (2.1-5.6) ppb (Guo et al., 2016; Wang et al., 2017; Yang et al., 2019; Zeng et al., 2019b) and the background NCP region (3.5-3.7 ppb) conducted 3-6 years before our experiments (Yang et al., 2017; Wang et al., 2020). The HCHO photolysis rate of $8.3 \times 10^{6} \mathrm{molec} \mathrm{cm}^{-3} \mathrm{~s}^{-1}$ at noon on pollution days is higher than pervious results in a suburban site of Beijing during winter $\left(\sim 6.7 \times 10^{6} \mathrm{molec} \mathrm{cm}^{-3} \mathrm{~s}^{-1}\right.$ at noon) (Tan et al., 2018) and an industrial zone of southeastern China during winter $\left(1.6 \times 10^{6}\right.$ molec $\mathrm{cm}^{-3} \mathrm{~s}^{-1}$ averaged over 7:00-16:00) (Zheng et al., 2020). This indicates that high reactive VOC emissions over the NCP region can drive fast photochemistry in cold seasons on a regional scale by acting as radicals in addition to precursors. 


\section{Discussion and implication}

From the results above, we conclude that the abrupt increase of PAN at the SDZ site during cold days is a result of local enhanced photochemistry from increased VOC precursor concentrations and $\mathrm{HO}_{\mathrm{x}}$ levels under a warmer, wetter atmosphere and southern wind anomalies. On the mornings of pollution days, the mean concentration of $\mathrm{CH}_{3} \mathrm{CHO}$ was 2.8 times that on clean days. This increase was due to persistent southern wind in the previous days, bringing polluted air mass from urban region to the SDZ site. Besides, the $\mathrm{P}\left[\mathrm{HO}_{\mathrm{x}}\right]$ on pollution days was about 2 times that during clean days, owing to enhanced photolysis of $\mathrm{HCHO}$ and $\mathrm{HONO}$ though weaker radiation at that time. The increases in $\mathrm{CH}_{3} \mathrm{CHO}$ level and $\mathrm{P}\left[\mathrm{HO}_{\mathrm{x}}\right]$ on pollution days could virtually explain the enhanced net chemical formation rate (6.3 times that on clean days) with nearly constant reaction rate coefficient. Accelerated photochemistry by enhanced $\mathrm{NO}_{\mathrm{x}}$ and VOCs facilitates the rapid increase of PAN at the background site during cold seasons.

Particularly, our study demonstrates the dominant role of $\mathrm{HCHO}$ photolysis in $\mathrm{HO}_{\mathrm{x}}$ production during autumn at the rural NCP region. The enhanced HCHO photolysis on pollution days not only promotes chemical production of PAN, but also accelerates formation of other secondary pollutants. This is evidenced by the synchronously increased concentrations of PAN, $\mathrm{PM}_{2.5}$ and $\mathrm{O}_{3}$ on pollution days, highlighting the importance of HCHO photolysis from VOC oxidation in secondary pollutant formation under low- $\mathrm{NO}_{\mathrm{x}}$ conditions even during cold days. On the other hand, $\mathrm{HCHO}$ itself is also a photochemical product mainly formed through oxidation by NMHCs. Its high level during pollution days and strong correlation with PAN imply the potential role of accelerated photochemistry by enhanced $\mathrm{NO}_{\mathrm{x}}$ and VOCs in increases of photochemical pollutants.

The importance of HCHO photolysis on secondary pollutants as we demonstrated from the SDZ site measurement could also be applicable to regions with low $\mathrm{NO}_{\mathrm{x}}$ emissions but high reactive VOC emissions during cold seasons. The Chinese government has conducted effective $\mathrm{NO}_{\mathrm{x}}$ emission controls since 2013 and summertime VOC emission controls in recent years. Our results show that it is also imperative to implement the VOC controls out of the summer season to avoid the unexpectedly enhanced photochemistry with decreasing $\mathrm{NO}_{\mathrm{x}}$ emissions over the NCP region.

\section{Conclusion}

We performed an integrated observation experiment at a rural site in the northern border of the NCP region in autumn 2020. The observed results show abrupt increases of PAN over two pollution days with increasing ratios of $244 \%$ and $178 \%$ over the morning hours (8:00-12:00). Meteorlogical reanalysis data together with surface meteorological observations reveal that southwesterlies prevailed in the NCP during pollution days, accompanied by a warmer and wetter atmosphere. However, the abrupt increases of PAN on pollution days impossibly resulted from direct PAN transport from the urban region, as the time when the prevailing wind turned to southerlies was too late. Using $\mathrm{CO}$ as a tracer to exclude impact from physical transport of PAN from the urban region, we find that the net chemical formation rates was $0.45 \mathrm{ppb} \mathrm{h}^{-1}$ on the morning of 
pollution days, which was 6.3 times that on clean days. Therefore, the strong local photochemistry is the main cause of PAN enhancement on the morning of the two pollution days.

Further investigation reveals that $\mathrm{CH}_{3} \mathrm{CHO}$ oxidation by $\mathrm{OH}$ is the major pathways of PA formation at the SDZ site. The $\mathrm{C}_{3} \mathrm{H}_{6}$ and $\mathrm{CH}_{3} \mathrm{CHO}$ concentrations during 10/16 to 10/20 exhibited increasing trends, demonstrating the cumulative effect and regional transport from urban region under a meteorological condition of persistent southerlies during late morning to evening. Statistical results show that the mean $\mathrm{CH}_{3} \mathrm{CHO}$ concentration on the morning of pollutions days was 2.8 times that on clean days. Additionally, the $\mathrm{P}\left[\mathrm{HO}_{\mathrm{x}}\right]$ on pollution days was about 2 times that during clean days, owing to enhanced photolysis of HCHO and HONO despite weaker radiation at that time. Consequently, the abrupt increase of PAN at the SDZ site during cold days is a result of local enhanced photochemistry from increases of VOC precursor concentrations and $\mathrm{HO}_{\mathrm{x}}$ levels under a warmer and wetter atmosphere and south wind anomalies. Our study explores the cause of abrupt increase of PAN concentration at a background site of the NCP region during cold days, and emphasizes the important role of HCHO in secondary pollutant formation in cold seasons, which is vital for understanding winter photochemistry under low $\mathrm{NO}_{\mathrm{x}}$ emissions.

\section{Data availability}

400 The ERA5 data are accessed from https://cds.climate.copernicus.eu/. The observation data for $\mathrm{O}_{\mathrm{x}}$ at the MY and urban site are obtained from the Beijing Municipal Ecological and Environmental Monitoring Center (http://www.bjmemc.com.cn/). The observation data used in this study can be accessed via https://doi.org/10.7910/DVN/EPAGNB.

\section{Author contributions}

YQ and ZM designed the study. YQ carried out the analysis and wrote the paper. YQ, ZM, MH, JS, PT, WP and HZ together 405 conducted the observation experiment. KL, JZ, TH, YT and HL helped interpret the results. ZM and KL helpled revise this paper.

\section{Competing interests}

The authors declare that they have no conflict of interest.

\section{Acknowledgements}

410 The authors would like to thank the staff of the Shangdianzi station for their excellent work. This research was supported by the Beijing Natural Science Foundation (Grant No. 8194078), the Open fund by Jiangsu Key Laboratory of Atmospheric 
Environment Monitoring and Pollution Control (Grant No. KHK2001) and the National Natural Science Foundation of China (Grant No. 41475135).

\section{References}

415 Alicke, B., Geyer, A., Hofzumahaus, A., Holland, F., Konrad, S., Pätz, H. W., Schäfer, J., Stutz, J., Volz-Thomas, A., and Platt, U.: OH formation by HONO photolysis during the BERLIOZ experiment, Journal of Geophysical Research: Atmospheres, 108, PHO 3-1-PHO 3-17, https://doi.org/10.1029/2001JD000579, 2003.

Chen, Y. J., Ma, Q. L., Lin, W. L., Xu, X. B., Yao, J., and Gao, W.: Measurement report: Long-term variations in carbon monoxide at a background station in China's Yangtze River Delta region, Atmospheric Chemistry and Physics, 20, 15969-15982, 10.5194/acp-20-15969-2020, 2020.

Dang, R., Liao, H., and Fu, Y.: Quantifying the anthropogenic and meteorological influences on summertime surface ozone in China over 2012-2017, Science of The Total Environment, 754, 142394, https://doi.org/10.1016/j.scitotenv.2020.142394, 2021.

Duan, J., Guo, S., Tan, J., Wang, S., and Chai, F.: Characteristics of atmospheric carbonyls during haze days in Beijing, China, Atmospheric Research, 114-115, 17-27, https://doi.org/10.1016/j.atmosres.2012.05.010, 2012.

Edwards, P. M., Brown, S. S., Roberts, J. M., Ahmadov, R., Banta, R. M., deGouw, J. A., Dubé, W. P., Field, R. A., Flynn, J. H., Gilman, J. B., Graus, M., Helmig, D., Koss, A., Langford, A. O., Lefer, B. L., Lerner, B. M., Li, R., Li, S.-M., McKeen, S. A., Murphy, S. M., Parrish, D. D., Senff, C. J., Soltis, J., Stutz, J., Sweeney, C., Thompson, C. R., Trainer, M. K., Tsai, C., Veres, P. R., Washenfelder, R. A., Warneke, C., Wild, R. J., Young, C. J., Yuan, B., and Zamora, R.: High winter ozone pollution from carbonyl photolysis in an oil and gas basin, Nature, 514, 351-354, 10.1038/nature13767, 2014.

Fischer, E. V., Jacob, D. J., Yantosca, R. M., Sulprizio, M. P., Millet, D. B., Mao, J., Paulot, F., Singh, H. B., Roiger, A., Ries, L., Talbot, R. W., Dzepina, K., and Deolal, S. P.: Atmospheric peroxyacetyl nitrate (PAN): a global budget and source attribution, Atmospheric Chemistry and Physics, 14, 2679-2698, 10.5194/acp-14-2679-2014, 2014.

Gao, J., Wang, T., Ding, A. J., and Liu, C. B.: Observational study of ozone and carbon monoxide at the summit of mount Tai (1534m a.s.l.) in central-eastern China, Atmospheric Environment, 39, 4779-4791, 10.1016/j.atmosenv.2005.04.030, 2005.

Guo, S., Chen, M., and Tan, J.: Seasonal and diurnal characteristics of atmospheric carbonyls in Nanning, China, Atmospheric Research, 169, 46-53, https://doi.org/10.1016/j.atmosres.2015.09.028, 2016.

440 Hendrick, F., Müller, J. F., Clémer, K., Wang, P., De Mazière, M., Fayt, C., Gielen, C., Hermans, C., Ma, J. Z., Pinardi, G., Stavrakou, T., Vlemmix, T., and Van Roozendael, M.: Four years of ground-based MAX-DOAS observations of HONO and NO<sub>2</sub> in the Beijing area, Atmos. Chem. Phys., 14, 765-781, 10.5194/acp-14-765-2014, 2014. 
Heuss, J. M. and Glasson, W. A.: Hydrocarbon reactivity and eye irritation, Environmental Science \& Technology, 2, 11091116, 1968.

Hu, B., Liu, T., Hong, Y., Xu, L., Li, M., Wu, X., Wang, H., Chen, J., and Chen, J.: Characteristics of peroxyacetyl nitrate (PAN) in a coastal city of southeastern China: Photochemical mechanism and pollution process, Science of the Total Environment, 719, 10.1016/j.scitotenv.2020.137493, 2020.

Kim, S., VandenBoer, T. C., Young, C. J., Riedel, T. P., Thornton, J. A., Swarthout, B., Sive, B., Lerner, B., Gilman, J. B., Warneke, C., Roberts, J. M., Guenther, A., Wagner, N. L., Dubé, W. P., Williams, E., and Brown, S. S.: The primary and recycling sources of $\mathrm{OH}$ during the NACHTT-2011 campaign: HONO as an important $\mathrm{OH}$ primary source in the wintertime, Journal of Geophysical Research: Atmospheres, 119, 6886-6896, https://doi.org/10.1002/2013JD019784, 2014.

Li, K., Jacob, D. J., Shen, L., Lu, X., De Smedt, I., and Liao, H.: Increases in surface ozone pollution in China from 2013 to 2019: anthropogenic and meteorological influences, Atmospheric Chemistry and Physics, 20, 11423-11433, 10.5194/acp-20-11423-2020, 2020.

Li, K., Jacob, D. J., Liao, H., Qiu, Y., Shen, L., Zhai, S., Bates, K. H., Sulprizio, M. P., Song, S., Lu, X., Zhang, Q., Zheng, B., Zhang, Y., Zhang, J., Lee, H. C., and Kuk S. K., Ozone pollution in the North China Plain spreading into the latewinter haze season, PNAS, 118, e2015797118, 2021.

Ling, Z. H., Zhao, J., Fan, S. J., and Wang, X. M.: Sources of formaldehyde and their contributions to photochemical O3 formation at an urban site in the Pearl River Delta, southern China, Chemosphere, 168, 1293-1301, https://doi.org/10.1016/j.chemosphere.2016.11.140, 2017.

Liu, L., Wang, X., Chen, J., Xue, L., Wang, W., Wen, L., Li, D., and Chen, T.: Understanding unusually high levels of peroxyacetyl nitrate (PAN) in winter in Urban Jinan, China, Journal of Environmental Sciences, 71, 249-260, https://doi.org/10.1016/j.jes.2018.05.015, 2018.

Liu, J., Liu, Z., Ma, Z., Yang, S., Yao, D., Zhao, S., Hu, B., Tang, G., Sun, J., Cheng, M., Xu, Z., and Wang, Y., Detailed budget analysis of HONO in Beijing, China: Implication on atmosphere oxidation capacity in polluted megacity, Atmospheric Environment, 244, 117957, 2021.

Lu, K., Fuchs, H., Hofzumahaus, A., Tan, Z., Wang, H., Zhang, L., Schmitt, S. H., Rohrer, F., Bohn, B., Broch, S., Dong, H., Gkatzelis, G. I., Hohaus, T., Holland, F., Li, X., Liu, Y., Liu, Y., Ma, X., Novelli, A., Schlag, P., Shao, M., Wu, Y., Wu, Z., Zeng, L., Hu, M., Kiendler-Scharr, A., Wahner, A., and Zhang, Y.: Fast Photochemistry in Wintertime Haze: Consequences for Pollution Mitigation Strategies, Environmental Science \& Technology, 53, 10676-10684, 10.1021/acs.est.9b02422, 2019.

Lu, X., Zhang, L., Wang, X., Gao, M., Li, K., Zhang, Y., Yue, X., and Zhang, Y.: Rapid Increases in Warm-Season Surface Ozone and Resulting Health Impact in China Since 2013, Environmental Science \& Technology Letters, 7, 240-247, 10.1021/acs.estlett.0c00171, 2020. 
Ma, Z., Xu, J., Quan, W., Zhang, Z., Lin, W., and Xu, X.: Significant increase of surface ozone at a rural site, north of eastern China, Atmospheric Chemistry \& Physics, 16, 3969-3977, 2016.

Madronich, S., Flocke, S., The role of solar radiation in atmospheric chemistry. In: Boule, P. (Ed.), Handbook of Environmental Chemistry. Springer-Verlag, Heidelberg, pp. 1-26, 1999.

Pang, X., Mu, Y., Zhang, Y., Lee, X., and Yuan, J.: Contribution of isoprene to formaldehyde and ozone formation based on its oxidation products measurement in Beijing, China, Atmospheric Environment, 43, 2142-2147, https://doi.org/10.1016/j.atmosenv.2009.01.022, 2009.

Qian, X., Shen, H., and Chen, Z.: Characterizing summer and winter carbonyl compounds in Beijing atmosphere, Atmospheric Environment, 214, 116845, https://doi.org/10.1016/j.atmosenv.2019.116845, 2019.

Qiu, Y., Lin, W., Li, K., Chen, L., Yao, Q., Tang, Y., and Ma, Z.: Vertical characteristics of peroxyacetyl nitrate (PAN) from a 250-m tower in northern China during September 2018, Atmospheric Environment, 213, 55-63, 10.1016/j.atmosenv.2019.05.066, 2019a.

Qiu, Y., Ma, Z., and Li, K.: A modeling study of the peroxyacetyl nitrate (PAN) during a wintertime haze event in Beijing, China, Science of the Total Environment, 650, 1944-1953, 10.1016/j.scitotenv.2018.09.253, 2019b.

Qiu, Y., Ma, Z., Lin, W., Quan, W., Pu, W., Li, Y., Zhou, L., and Shi, Q.: A study of peroxyacetyl nitrate at a rural site in Beijing based on continuous observations from 2015 to 2019 and the WRF-Chem model, Frontiers of Environmental Science \& Engineering, 14, 10.1007/s11783-020-1250-0, 2020a.

Qiu, Y., Ma, Z., Li, K., Lin, W., Tang, Y., Dong, F., and Liao, H.: Markedly Enhanced Levels of Peroxyacetyl Nitrate (PAN) During COVID-19 in Beijing, Geophysical Research Letters, 47, 10.1029/2020gl089623, 2020b.

Qiu, X., Wang, S., Ying, Q., Duan, L., Xing, J., Cao, J., Wu, D., Li, X., Xing, C., Yan, X., Liu, C., and Hao, J.: Importance of Wintertime Anthropogenic Glyoxal and Methylglyoxal Emissions in Beijing and Implications for Secondary Organic Aerosol Formation in Megacities, Environmental Science \& Technology, 54, 11809-11817, 10.1021/acs.est.0c02822, 2020c.

Rao, Z., Chen, Z., Liang, H., Huang, L., and Huang, D.: Carbonyl compounds over urban Beijing: Concentrations on haze and non-haze days and effects on radical chemistry, Atmospheric Environment, 124, 207-216, https://doi.org/10.1016/j.atmosenv.2015.06.050, 2016.

Schnell, R. C., Oltmans, S. J., Neely, R. R., Endres, M. S., Molenar, J. V., and White, A. B.: Rapid photochemical production of ozone at high concentrations in a rural site during winter, Nature Geoscience, 2, 120-122, 2009.

Seinfeld, J. H., Pandis, S. N., Atmospheric chemistry and physics: From air pollution to climate change. John Wiley \&Sons, Inc., 2006.

Sheng, J., Zhao, D., Ding, D., Li, X., Huang, M., Gao, Y., Quan, J., and Zhang, Q.: Characterizing the level, photochemical reactivity, emission, and source contribution of the volatile organic compounds based on PTR-TOF-MS during winter haze period in Beijing, China, Atmospheric Research, 212, 54-63, https://doi.org/10.1016/j.atmosres.2018.05.005, 2018. 
Sun, M., Cui, J. n., Zhao, X., and Zhang, J.: Impacts of precursors on peroxyacetyl nitrate (PAN) and relative formation of PAN to ozone in a southwestern megacity of China, Atmospheric Environment, 231, 10.1016/j.atmosenv.2020.117542, 2020.

Tan, Z., Rohrer, F., Lu, K., Ma, X., and Zhang, Y.: Wintertime photochemistry in Beijing: Observations of ROx radical concentrations in the North China Plain during the BEST-ONE campaign, Atmospheric Chemistry and Physics, 1-33, 2018.

515 Taylor, O. C.: Importance of peroxyacetyl nitrate (PAN) as a phytotoxic air pollutant, Air Repair, 19, 347-351, 1969.

Wang, Y., Hu, B., Tang, G., Ji, D., Zhang, H., Bai, J., Wang, X., and Wang, Y.: Characteristics of ozone and its precursors in Northern China: A comparative study of three sites, Atmospheric Research, 132-133, 450-459, https://doi.org/10.1016/j.atmosres.2013.04.005, 2013.

Wang, C., Huang, X.-F., Han, Y., Zhu, B., and He, L.-Y.: Sources and Potential Photochemical Roles of Formaldehyde in an Urban Atmosphere in South China, Journal of Geophysical Research: Atmospheres, 122, 11,934-911,947, https://doi.org/10.1002/2017JD027266, 2017.

Wang, J., Sun, S., Zhang, C., Xue, C., Liu, P., Zhang, C., Mu, Y., Wu, H., Wang, D., Chen, H., and Chen, J.: The pollution levels, variation characteristics, sources and implications of atmospheric carbonyls in a typical rural area of North China Plain during winter, Journal of Environmental Sciences, 95, 256-265, https://doi.org/10.1016/j.jes.2020.05.003, 2020.

Wei, W., Zang, J., Wang, X., and Cheng, S.: Peroxyacetyl nitrate (PAN) in the border of Beijing, Tianjin and Hebei of China: Concentration, source apportionment and photochemical pollution assessment, Atmospheric Research, 246, 10.1016/j.atmosres.2020.105106, 2020.

Worden, H. M., Deeter, M. N., Frankenberg, C., George, M., Nichitiu, F., Worden, J., Aben, I., Bowman, K. W., Clerbaux, C., Coheur, P. F., de Laat, A. T. J., Detweiler, R., Drummond, J. R., Edwards, D. P., Gille, J. C., Hurtmans, D., Luo, M., Martinez-Alonso, S., Massie, S., Pfister, G., and Warner, J. X.: Decadal record of satellite carbon monoxide observations, Atmospheric Chemistry and Physics, 13, 837-850, 10.5194/acp-13-837-2013, 2013.

Xu, X. B., Zhang, H. L., Lin, W. L., Wang, Y., Xu, W. Y., and Jia, S. H.: First simultaneous measurements of peroxyacetyl nitrate (PAN) and ozone at Nam Co in the central Tibetan Plateau: impacts from the PBL evolution and transport processes, Atmospheric Chemistry and Physics, 18, 5199-5217, 10.5194/acp-18-5199-2018, 2018.

Xue, C., Zhang, C., Ye, C., Liu, P., Catoire, V., Krysztofiak, G., Chen, H., Ren, Y., Zhao, X., Wang, J., Zhang, F., Zhang, C., Zhang, J., An, J., Wang, T., Chen, J., Kleffmann, J., Mellouki, A., and Mu, Y.: HONO Budget and Its Role in Nitrate Formation in the Rural North China Plain, Environmental Science \& Technology, 54, 11048-11057, 10.1021/acs.est.0c01832, 2020.

Xue, L., Wang, T., Wang, X., Blake, D. R., Gao, J., Nie, W., Gao, R., Gao, X., Xu, Z., Ding, A., Huang, Y., Lee, S., Chen, Y., Wang, S., Chai, F., Zhang, Q., and Wang, W.: On the use of an explicit chemical mechanism to dissect peroxy acetyl nitrate formation, Environmental Pollution, 195, 39-47, 10.1016/j.envpol.2014.08.005, 2014. 
Yang, X., Xue, L., Yao, L., Li, Q., Wen, L., Zhu, Y., Chen, T., Wang, X., Yang, L., Wang, T., Lee, S., Chen, J., and Wang, W.: Carbonyl compounds at Mount Tai in the North China Plain: Characteristics, sources, and effects on ozone formation, Atmospheric Research, 196, 53-61, https://doi.org/10.1016/j.atmosres.2017.06.005, 2017.

Yang, X., Xue, L., Wang, T., Wang, X., Gao, J., Lee, S., Blake, D. R., Chai, F., and Wang, W.: Observations and Explicit Modeling of Summertime Carbonyl Formation in Beijing: Identification of Key Precursor Species and Their Impact on Atmospheric Oxidation Chemistry, Journal of Geophysical Research: Atmospheres, 123, 1426-1440, https://doi.org/10.1002/2017JD027403, 2018.

Yang, Z., Cheng, H. R., Wang, Z. W., Peng, J., Zhu, J. X., Lyu, X. P., and Guo, H.: Chemical characteristics of atmospheric carbonyl compounds and source identification of formaldehyde in Wuhan, Central China, Atmospheric Research, 228, 95-106, https://doi.org/10.1016/j.atmosres.2019.05.020, 2019.

Zeng, L., Fan, G.-J., Lyu, X., Guo, H., Wang, J.-L., and Yao, D.: Atmospheric fate of peroxyacetyl nitrate in suburban Hong Kong and its impact on local ozone pollution, Environmental Pollution, 252, 1910-1919, https://doi.org/10.1016/j.envpol.2019.06.004, 2019a.

Zeng, P., Lyu, X., Guo, H., Cheng, H., Wang, Z., Liu, X., and Zhang, W.: Spatial variation of sources and photochemistry of formaldehyde in Wuhan, Central China, Atmospheric Environment, 214, 116826, https://doi.org/10.1016/j.atmosenv.2019.116826, 2019b.

Zhai, S., Jacob, D. J., Wang, X., Shen, L., Li, K., Zhang, Y., Gui, K., Zhao, T., and Liao, H.: Fine particulate matter (PM2.5) trends in China, 2013-2018: separating contributions from anthropogenic emissions and meteorology, Atmos. Chem. Phys., 19, 11031-11041, https://doi.org/10.5194/acp-19-11031-2019, 2019.

Zhang, Y., Mu, Y., Liu, J., and Mellouki, A.: Levels, sources and health risks of carbonyls and BTEX in the ambient air of Beijing, China, Journal of Environmental Sciences, 24, 124-130, https://doi.org/10.1016/S1001-0742(11)60735-3, 2012.

Zhang, H., Xu, X., Lin, W., and Wang, Y.: Wintertime peroxyacetyl nitrate (PAN) in the megacity Beijing: Role of photochemical and meteorological processes, Journal of Environmental Sciences, 26, 83-96, 10.1016/s10010742(13)60384-8, 2014.

Zhang, G., Mu, Y., Zhou, L., Zhang, C., Zhang, Y., Liu, J., Fang, S., and Yao, B.: Summertime distributions of peroxyacetyl nitrate (PAN) and peroxypropionyl nitrate (PPN) in Beijing: Understanding the sources and major sink of PAN, Atmospheric Environment, 103, 289-296, 10.1016/j.atmosenv.2014.12.035, 2015.

Zhang, B., Zhao, B., Zuo, P., Zhi, H., and Zhang, J.: Ambient peroxyacyl nitrate concentration and regional transportation in Beijing, Atmospheric Environment, S1352231017305022, 2017.

Zhang, B., Zhao, X., and Zhang, J.: Characteristics of peroxyacetyl nitrate pollution during a 2015 winter haze episode in Beijing, Environmental Pollution, 244, 379-387, 10.1016/j.envpol.2018.10.078, 2019.

Zhang, G., Xia, L., Zang, K., Xu, W., Zhang, F., Liang, L., Yao, B., Lin, W., and Mu, Y.: The abundance and interrelationship of atmospheric peroxyacetyl nitrate (PAN), peroxypropionyl nitrate (PPN), O-3, and NOy during the wintertime in Beijing, China, Science of the Total Environment, 718, 10.1016/j.scitotenv.2020.137388, 2020a. 
https://doi.org/10.5194/acp-2021-359

Preprint. Discussion started: 23 June 2021

(c) Author(s) 2021. CC BY 4.0 License.

(c) (1)

Zhang, J., Guo, Y., Qu, Y., Chen, Y., Yu, R., Xue, C., Yang, R., Zhang, Q., Liu, X., Mu, Y., Wang, J., Ye, C., Zhao, H., Sun, Q., Wang, Z., and An, J.: Effect of potential HONO sources on peroxyacetyl nitrate (PAN) formation in eastern China in winter, Journal of Environmental Sciences, 94, 81-87, 10.1016/j.jes.2020.03.039, 2020b.

Zhao, X., Gao, T., and Zhang, J.: Heterogeneous reaction of peroxyacetyl nitrate (PAN) on soot, Chemosphere, 177, 339-346, https://doi.org/10.1016/j.chemosphere.2017.03.001, 2017.

Zheng, J., Shi, X., Ma, Y., Ren, X., Jabbour, H., Diao, Y., Wang, W., Ge, Y., Zhang, Y., and Zhu, W.: Contribution of nitrous acid to the atmospheric oxidation capacity in an industrial zone in the Yangtze River Delta region of China, Atmos. Chem. Phys., 20, 5457-5475, 10.5194/acp-20-5457-2020, 2020.

Zhou, X., Tan, J., Qin, J., Hu, J., Duan, J., and Chen, R.: Impact of emissions controls on ambient carbonyls during the AsiaPacific Economic Cooperation summit in Beijing, China, Environmental Science and Pollution Research, 26, 1187511887, 10.1007/s11356-019-04577-5, 2019.

Zhu, H., Gao, T., and Zhang, J.: Wintertime characteristic of peroxyacetyl nitrate in the Chengyu district of southwestern China, Environmental Science and Pollution Research, 25, 23143-23156, 10.1007/s11356-018-2412-5, 2018. 